\title{
NO-cGMP signalling and cancer therapy
}

\author{
Ka Bian*, Alex Sotolongo, Huy Lam, Haijie Xiao, Dandan Zhang, Jun Liu, Ferid Murad \\ From 6th International Conference on cGMP: Generators, Effectors and Therapeutic Implications \\ Erfurt, Germany. 28-30 June 2013
}

\section{Background}

The nitric oxide (NO) and 3',5'-cyclic guanosine monophosphate (cGMP) pathway is one of the best characterized signalling cascades that plays a central role in several physiological processes such as vasodilation, neurotransmission, and embryonic development. Soluble guanylyl cyclase (sGC) is the key receptor for NO with $\alpha 1 \beta 1$ as predominate heterodimer for the function. Nitric oxide binds to the ferrous heme at histidine 105 of the $\beta 1$ subunit and leads to at least a 200-fold increase in sGC activity and cGMP production [1]. On the other hand, the effects of NO can be attributed to cGMP-independent pathway which is mainly mediated by reactive oxygen/nitrogen species such as highly reactive peroxynitrite (ONOO-) [2]. The role of NO and cGMP signalling in tumour biology has been extensively studied during the past three decades, however a consensus regarding the precise role that the NO/cGMP signalling axis plays in neoplastic transformation has not been reached. Simple applications of NO or cGMP regulating reagents to various cancer cell lines or animal models has generated controversial results. We suggest several factors are contributing to this ambiguity: First, although the NO participates in normal signalling (e.g., vasodilatation and neurotransmission), $\mathrm{NO}$ is also a cytotoxic or apoptotic molecule when produced at high concentrations by inducible nitric oxide synthase (iNOS or NOS-2). Also, the cGMP-dependent (NO/sGC/cGMP pathway) and cGMP-independent (NO/oxidative pathway) components may vary among different tissues and cell types. Furthermore, solid tumours contain two compartments: the parenchyma (neoplastic cells) and the stroma (nonmalignant supporting tissues including connective tissue, blood vessels, and, inflammatory cells) with differing NO biology. Therefore, the NO/sGC/cGMP signalling molecules in tumours as well as the surrounding tissue

\footnotetext{
*Correspondence: bcmkxb@gwu.edu

Department of Biochemistry and Molecular Medicine, George Washington University,2300 I Street, NW; Ross Hall 543; Washington, DC 20037, USA
}

must be further characterized before targeting this signalling pathway for tumour therapy.

\section{Results}

Our database analysis shows that by comparing with respective normal tissues, the expression of NO-cGMP signalling molecules in different human cancers varies significantly (Figure 1). The expression of NO synthase (NOS)-1 is down-regulated in brain, kidney and lung cancer specimens. NOS-2 is up-regulated in breast cancer but decreased in lung cancer. NOS- 3 is higher in malignant intestine tumour, but inhibited in both brain and breast cancers. Despite the fact that sGC is an obligate heterodimer for function, sGC subunits are differentially expressed in cancers with sGC $\alpha 1$ being lower in brain, lung and breast cancers, but higher in prostate and ovarian cancers while sGC $\beta 1$ is attenuated in brain, lung, liver, breast cancers, but elevated in lymphoma, ovarian, head and neck cancers. The data regarding membrane bound guanylyl cyclases shows that NPR2 is up-regulated in brain cancer with non-change of NPR1; NPR1 is higher and NPR2 is lower in ovarian cancer; both NPR1 and NPR2 are downregulated in breast cancer; and NPR1 expression is diminished in lung and kidney cancers. As the key molecules downstream of cGMP, PRKG1 is over-expressed in brain cancer and decreased in lung, breast and ovarian cancers. PRKG2 is only changed in myeloid leukaemia. As the major cGMP specific phosphodiesterase, PDE-5 shows broad depression in brain, lung, prostate, breast, malignant tumour of Intestine and myeloid leukaemia.

We have performed initial experiments to prove our hypothesis that restoration of normal NO-cGMP signalling blocks the aggressive course of cancer [3]. Pharmacologically manipulating endogenous cGMP generation in glioma cells through either stimulating pGC (NPR1 and NPR2) by ANP/BNP, or blocking PDE-5 by IBMX/ zaprinast caused significant inhibition of proliferation and colony formation of glioma U87 cells. Genetically restoring $\mathrm{sGC}$ expression also inversely correlated with 


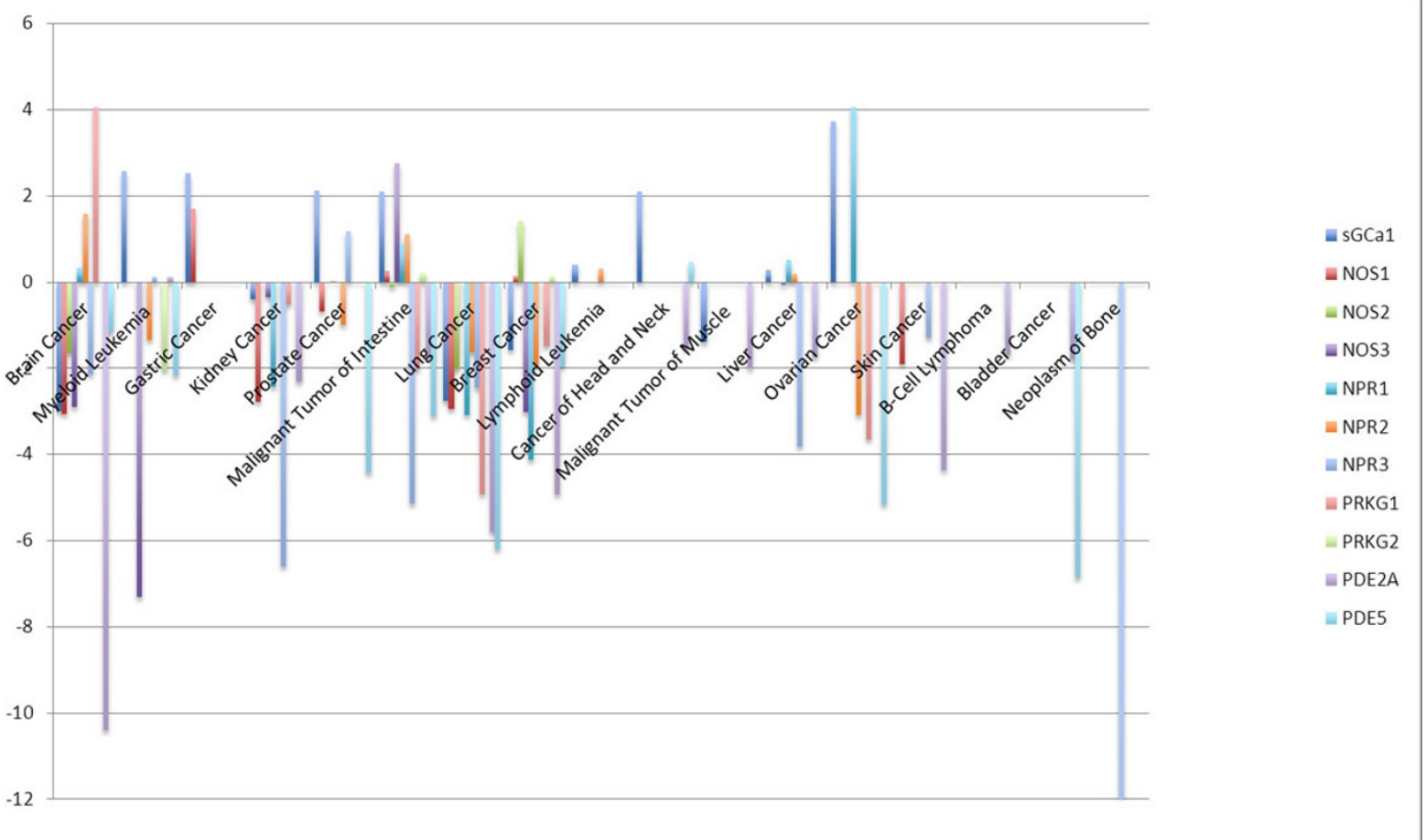

Figure 1 The changes of NO-cGMP signalling molecules in different human cancers compared to correspond normal tissues.

glioma cells growth. Orthotopic implantation of glioma cells transfected with an active mutant form of sGC (sGC $\alpha 1 \beta 1$ cys-105) in athymic mice increased the survival time by 4-fold over the control. Histological analysis of xenografts overexpressing $\alpha 1 \beta 1$ cys-105 sGC revealed changes in cellular architecture which resemble the morphology of normal cells. In addition, a decrease in angiogenesis contributed to glioma inhibition by sGC/cGMP therapy.

\section{Conclusion}

Our study proposes a new concept that suppressed expression of sGC a key enzyme in the NO/cGMP pathway, may be associated with an aggressive course of glioma. The sGC/cGMP signalling-targeted therapy may be a favourable alternative to chemotherapy and radiotherapy for glioma and perhaps other tumours such as breast, lung and pancreatic cancers.

Published: 29 August 2013

\section{References}

1. Bian K, Murad F: Nitric oxide (NO)-biogeneration, regulation, and relevance to human diseases. Front Biosci 2003, 8:264-278.

2. Bian K, Gao Z, Weisbrodt N, Murad F: The nature of heme/iron-induced protein tyrosine nitration. Proc Natl Acad Sci USA 2003, 100:5712-5717.

3. Zhu H, Li JT, Zheng F, Martin E, Kots AY, Krumenacker JS, Choi BK, McCutcheon IE, Weisbrodt N, Bögler O, Murad F, Bian K: Restoring soluble guanylyl cyclase expression and function blocks the aggressive course of glioma. Mol Pharmacol 2011, 80:1076-1084.

doi:10.1186/2050-6511-14-S1-P9

Cite this article as: Bian et al:: NO-cGMP signalling and cancer therapy. BMC Pharmacology and Toxicology 2013 14(Suppl 1):P9.

\section{Submit your next manuscript to BioMed Central} and take full advantage of:

- Convenient online submission

- Thorough peer review

- No space constraints or color figure charges

- Immediate publication on acceptance

- Inclusion in PubMed, CAS, Scopus and Google Scholar

- Research which is freely available for redistribution 